NBER WORKING PAPER SERIES

\title{
MONETARY POLICY AND REAL STABILIZATION
}

\author{
Lars E. O. Svensson \\ Working Paper 9486 \\ http://www.nber.org/papers/w9486
NATIONAL BUREAU OF ECONOMIC RESEARCH 1050 Massachusetts Avenue Cambridge, MA 02138
February 2003

Presented at "Rethinking Stabilization Policy," a symposium sponsored by the Federal Reserve Bank of Kansas City and held at Jackson Hole, Wyoming, August 29-31, 2002. I thank Alan Auerbach, Claes Berg, Villy Bergstr(om, Alan Blinder, Guy Debelle, Allan Meltzer and Lawrence Summers for comments, and Kathleen DeGennaro for editorial and secretarial assistance. Financial support from Princeton University's Center for Economic Policy Studies is gratefully acknowledged. The views expressed herein are those of the authors and not necessarily those of the National Bureau of Economic Research.

(C)2003 by Lars E. O. Svensson. All rights reserved. Short sections of text not to exceed two paragraphs, may be quoted without explicit permission provided that full credit including notice, is given to the source. 
Monetary Policy and Real Stabilization

Lars E. O. Svensson

NBER Working Paper No. 9486

February 2003

JEL No. E42, E52, E58

\begin{abstract}
$\underline{\text { ABSTRACT }}$
Monetary policy can achieve average inflation equal to a given inflation target and, at best, a good compromise between inflation variability and output-gap variability. Monetary policy cannot completely stabilize either inflation or the output gap. Increased credibility in the form of inflation expectations anchored on the inflation target will reduce the variability of inflation and the output gap.
\end{abstract}

Central banks can improve transparency and accountability by specifying not only an inflation target but also the dislike of output-gap variability relative to inflation variability.

Central banks can best achieve both the long-run inflation target and the best compromise between inflation and output-gap stability by engaging in "forecast targeting," where the bank selects the feasible combination of inflation and output-gap projections that minimize the loss function and the corresponding instrument-rate plan and sets the instrument-rate accordingly. Forecast targeting implies that the instrument responds to all information that significantly affects the projections of inflation and the output gap. Therefore it cannot be expressed in terms of a simple instrument rule, like a Taylor rule.

The objective of financial stability, including a well-functioning payment system, can conveniently be considered as a restriction on monetary policy that does not bind in normal times, but does bind in times of financial crises. By producing and publishing Financial Stability Reports with indicators of financial stability, the central bank can monitor the degree of financial stability and issue warnings to concerned agents and authorities in due time and this way avoid deteriorating financial stability.

Forecast targeting implies that asset-price developments and potential asset-price bubbles are taken into account and responded to the extent that they are deemed to affect the projections of the target variables, inflation and the output gap. In most cases, it will be difficult to make precise judgments, though, especially to identify bubbles with reasonable certainty.

The zero bound, liquidity traps and risks of deflation are serious concerns for a monetary policy aimed at low inflation. Forecast targeting with a symmetric positive inflation target keeps the risk of the zero bound, liquidity traps and deflation small. Prudent central banks may want to prepare in advance contingency plans for situations when a series of bad shocks substantially increases the risk of falling into a liquidity trap, as well as contingency plans escaping from a liquidity trap. An open economy, for instance, Japan, can use the foolproof way of escaping from a liquidity trap, with a price level target, a currency depreciation and a temporary exchange rate peg, and an exit strategy with a shift to inflation targeting when the price-level target has been reached.

Lars E.O. Svensson

Department of Economics

Princeton University

Princeton, NJ 08544-1021

and NBER

svensson@princeton.edu 


\section{Introduction}

Over the past two decades, maintenance of low inflation, "price stability," has become the principal focus of central banks around the world. At the same time, the view has emerged that monetary policy is better suited than fiscal policy for short-run stabilization purposes. This paper examines to what extent monetary policy can be directed at both "monetary stabilization," stabilizing inflation at a low level and "real stabilization," stabilizing output or, rather, the output gap and whether there are significant limitations on the use of monetary policy for real stabilization purposes. Section 2 discusses what a realistic view of monetary policy is, what monetary policy realistically can and cannot achieve, what the long-run and short-run tradeoffs are between inflation and output, what the appropriate objectives for monetary policy are, and what the role of credibility is for the tradeoff between inflation and output stabilization. Section 3 discusses how central banks can make the objectives of low and stable inflation and a stable output gap precise and the benefits thereof, how central banks can achieve the best outcome relative to these objectives by a procedure called "forecast targeting," and how this procedure is best implemented. Section 4 discusses how the objectives of financial stability and a well-functioning payment system can be taken into account and reconciled with the objectives of low and stable inflation and stable output gap, and to what extent central banks may want to respond to asset prices and bubbles. Section 5 discusses how the risks of hitting the zero (lower) interest rate bound and falling into a deflationary liquidity trap can be handled, how central banks can avoid falling into liquidity trap, and how central banks can escape from a liquidity trap if having fallen in. Section 6 summarizes the conclusions of the paper.

\section{A realistic view of monetary policy}

A discussion of whether stabilization of the real economy is consistent with a policy directed at low and stable inflation and how a central bank can achieve a desirable combination of real and monetary stability is more effective if it starts from a realistic view of what monetary policy can and cannot do. Such a view of monetary policy is also important in a discussion of the appropriate goals for monetary policy and in understanding why an increasing number of countries have selected low and stable inflation, "price stability," as the primary goal for monetary policy. ${ }^{1}$

\footnotetext{
${ }^{1}$ This section builds on Svensson [45].
} 
Let me start from the presumption that the ultimate objective of economic policy is to guarantee and enhance the citizens' welfare. This ultimate objective is often expressed as a number of separate goals which contribute to the citizens' welfare, for instance, efficient resource utilization, full and stable employment, high economic growth, price stability, equitable distribution of wealth and income, regional balance and environmental protection.

Monetary policy is part of economic policy. At first, one might think that it is natural that monetary policy has the same goals as overall economic policy. However, since monetary policy only has sustained or persistent effects on a limited number of variables affecting economic welfare, it is more suitable that monetary policy is assigned a limited number of goals. Specifying goals for monetary policy that it cannot achieve would be unproductive and could even be counterproductive. Instead, monetary policy is more effective if it is assigned goals that it can achieve and that are consistent with the ultimate objective for economic policy. In order to determine which goals are most suitable for monetary policy, one must therefore understand the effects of monetary policy and what monetary policy can and cannot achieve.

\subsection{How monetary policy affects the economy}

Monetary policy affects real and nominal variables through a number of channels, together referred to as the transmission mechanism of monetary policy. ${ }^{2}$ Central banks normally conduct monetary policy by setting a short nominal interest rate, the central bank's instrument rate (for instance, the federal funds rate in the U.S.). Suppose the central bank lowers the instrument rate. How is the economy affected? In the short term, domestic prices and domestic inflation in industrialized countries are relatively slow to change (or sticky). This means that private-sector inflation expectations for the short term are relatively sticky. This further implies that central banks, by controlling the short nominal interest rate, can also affect the short real interest rate: the difference between the short nominal rate and short-term inflation expectations. Via market expectations of future real rates, longer real rates are also affected. Thus, the lowering of the instrument rate normally lowers short and longer real interest rates, which will affect economic activity.

Furthermore, a reduction in the short interest rate normally depreciates the domestic currency and hence increases the nominal exchange rate (when the nominal exchange rate is expressed as units of domestic currency per unit of foreign currency). Since domestic prices in

\footnotetext{
${ }^{2}$ See Svensson [48] for a more formal discussion.
} 
practice are sticky (at least for industrialized countries), the domestic currency also depreciates in real terms. That is, the real exchange rate (the price of foreign goods and services in terms of domestic goods and services, or the price of tradable goods and services in terms of nontradable goods and services) also rises. The rise in the real exchange rate implies that the domestic price of imported and exported final goods increases (when the foreign-currency prices of imported and exported final goods are sticky). Since these goods enter the Consumer Price Index (CPI), this means that CPI inflation increases, the extent of which depends on these goods' share in the CPI. This is the so-called direct exchange rate channel to CPI inflation. The direct effect on CPI inflation usually occurs within about a year, or even quicker.

The fall in short and longer real interest rates mentioned above will stimulate consumption and investment and thereby increase aggregate demand and output in the economy (in practice, output is demand-determined in the short to medium term, at least in industrialized countries). This is the so-called real-interest-rate channel to aggregate demand. The rise in the real exchange rate makes domestically produced goods less expensive relative to foreign goods. This increases demand for export and for import-competing goods, which also adds to aggregate demand. This is the exchange rate channel to aggregate demand. The effects through these two channels usually occur in about a year or so.

The monetary policy literature has also discussed a so-called credit channel to aggregate demand. It works in the same direction as the pure real-interest-rate effect on aggregate demand. For simplicity, we can therefore include the credit channel in the above real-interest-rate channel to aggregate demand. The real-interest-rate channel also includes the effect on aggregate demand of wealth changes of interest-rate changes, for instance, effects via changes in the stock-market value.

\subsubsection{The impact of monetary policy on inflation}

Having traced the transmission channels to aggregate demand, let me discuss the effects on domestic inflation: the rate of change in the prices of the domestically produced goods and services. (Inflation in domestically produced tradable and nontradable final goods and services is the main component of CPI inflation; another substantial component is inflation in imported final goods.) We normally think of current output as determined mainly by aggregate demand in the short and medium term. Potential output is the hypothetical output level that would result in the absence of price and wage stickiness. It is largely determined by factors other 
than monetary policy. ${ }^{3}$ The output gap is the difference between current output and potential output. It can be seen as a measure of general excess demand in the economy. The above transmission channels to aggregate demand are hence also channels to the output gap. The increase in aggregate demand and the output gap will then lead to an increase in domestic inflation, because increased production increases the costs of production and because increased demand allows firms to increase prices. The increase in domestic inflation usually occurs within another year or so. This is the aggregate-demand channel to domestic inflation.

For a given output-gap level, domestic inflation is also independently affected by production costs, for instance wage costs and costs of imported intermediate inputs, like oil and raw materials. The fall in the exchange rate increases the cost of imported intermediate inputs as well as imported final goods, and the reduced purchasing power of wages may trigger increased wage demands. This can be called the production-cost channel to domestic inflation. Finally, price and wage setting are strongly affected by expectations of future inflation, since movements in the expected future price level are the obvious starting point for individual price and wage setting. This is the expectations channel to domestic inflation. Any increased inflation expectations that may be generated by the lowering of the instrument rate and the resulting increase in activity will then independently add to the effect on domestic inflation.

Thus, a reduction in the central bank's instrument rate affects the economy through a number of channels with different lags. The exchange rate and short and longer interest rates are usually immediately affected. Within about a year or less, there is an effect on CPI inflation through the direct exchange rate channel. As this first effect is working through, in about a year or so there is an increase in output and the output gap. Through that linkage, within another year or so there is a second effect on CPI inflation. Both effects are in the same direction, namely to increase inflation. However, the lags mentioned are only very rough rules of thumb. In practice, the lags and the strength of the effects through the different channels vary across channels and over time, and the effects are spread out over several quarters. For instance, the lag and the strength of the direct exchange rate effect on CPI inflation depends on the so-called pass-through of exchange rate changes: the degree to which importers pass on exchange rate changes to buyers rather than absorbing them in their profit margins. The pass-through varies considerably depending on the circumstances, for instance, with the perceived persistence of the

\footnotetext{
${ }^{3}$ Thus, potential output is distinct from a pure trend of actual output, and it will vary with real shocks to the economy. Potential output is defined inclusive of real imperfections like imperfect competition. Thus, potential ouput is lower than the efficient output level resulting under perfect competition and no frictions.
} 
exchange rate change, the size of the initial profit margins, and the price sensitivity of demand for imports. Furthermore, the economy is subject to a never-ending sequence of shocks and disturbances, directly and indirectly, to inflation and output, including price changes of raw materials, shifts in international capital flows, productivity changes, changes in indirect taxes, etc. Many of these shocks are quite difficult to identify, and many occur during the lag between instrument adjustment and effects on output and inflation. Thus, it is worth emphasizing that the central bank's control over inflation, output and other macro variables is quite imperfect.

\subsubsection{The long-term effects of monetary policy}

We have seen above how the central bank, by lowering its instrument rate, thereby reducing the short real interest rate and depreciating the currency, can increase aggregate demand and output, for a couple of years, say. Can the central bank indefinitely maintain a low instrument rate and depreciated currency and in this way stimulate the economy indefinitely? The answer is definitely no. In the longer term, the central bank must set its instrument rate so that on average the short real interest rate is equal to the average neutral real interest rate. The neutral real rate is the real interest rate that is consistent with output equal to potential output. Thus, the neutral real rate is the hypothetical real interest rate that would result in the absence of price stickiness and other frictions. It is largely determined by factors other than monetary policy. ${ }^{4}$ If the central bank tries to maintain a short real rate below the neutral real rate for too long, aggregate demand outstrips potential output, the economy becomes overheated, and inflation increases to high single-digit, then double-digit inflation, and eventually hyper-inflation. ${ }^{5}$ As history has demonstrated several times, a hyper-inflationary situation eventually results in a breakdown of the market system and a severe economic and financial crisis. Thus, sustained stimulation of the real economy through monetary policy is not a feasible option.

In the long term, monetary policy can only control nominal variables such as inflation and the exchange rate. In the long term, monetary policy cannot increase the average level or the growth rate of real variables such as GDP and employment, or affect the average level of the real exchange rate. There is evidence that monetary policy that leads to high and/or variable inflation is harmful to the real economy and to economic growth, by making the market

\footnotetext{
${ }^{4}$ Thus, similarly to potential output, the neutral real rate (also called the Wicksellian natural interest rate) is distinct from a pure trend of the actual real interest, and it will vary with real shocks to the economy.

5 The mirror image of this is a rapidly increasing rate of growth of the monetary base. In order to maintain the short real interest rate below the neutral rate, the central bank has to inject money into the economy at a rapidly increasing rate. At higher inflation rates, this money-growth channel to inflation becomes dominant.
} 
mechanism work less well and by creating unnecessary uncertainty. However, once monetary policy brings inflation down to relatively low and stable levels, monetary policy has no long-term effects on the average level and average growth rate of real variables. Nevertheless, monetary policy can affect the variability of real variables, as further discussed below.

\subsection{Suitable goals for monetary policy}

In the long run, output fluctuates around potential output, which is determined by factors other than monetary policy (except that, as already noted, bad and volatile monetary policy may well create a volatile and uncertain economic environment that deters investment and hence growth in potential output). Thus, there is a conspicuous difference between output targets and inflation targets for monetary policy. Whereas a long-run inflation target for monetary policy makes eminent sense and can be achieved, a long-run level or growth target for output different from potential output does not make sense for monetary policy, because it cannot be achieved. Thus, the long-run output target is given by potential output, which is largely independent of monetary policy. ${ }^{6}$ In the long term, monetary policy can at best provide a stable environment for the real economy. However, the fact that monetary policy has effects on the level of real variables in the short and medium term creates considerable tensions and temptations that need to be faced and handled.

A crucial ingredient in a stable environment for the real economy is a nominal anchor: an anchor for the nominal variables and private-sector expectations of future nominal variables. An increasing number of countries have found that low and stable inflation provides the best nominal anchor. The reason is that the alternative, higher inflation, has serious negative consequences. In practice, higher inflation always comes with higher variability in inflation. High and variable inflation impairs the capacity of the market mechanisms to achieve efficient resource allocation, and the ensuing uncertainty makes it more difficult for firms, consumers and savers to make the right decisions. It leads to arbitrary and inequitable redistributions of incomes and assets, for instance, a shift away from small savers to professional investors, and from tenants to owners of houses and property. Inflation is effectively theft from small savers and low-income groups. High inflation has no lasting positive effects, and the adverse effects eventually become unbearable. Numerous historical experiences have demonstrated that bringing inflation down from a high

\footnotetext{
${ }^{6}$ Increasing potential output towards the efficient output level is an important objective for economic policy, but other policies than monetary policy should be used, for instance, structural policies that improve the degree of competition on markets for goods and services and the workings of the labor market.
} 
level is costly; as a rule, a deep recession with high unemployment is required. Accordingly, it is important to avoid letting inflation take off in the first place. For these reasons, an increasing number of countries have specified "price stability" as the primary goal for monetary policy. ${ }^{7}$

However, completely disregarding the real consequences of monetary policy in the short and medium term and focusing exclusively on controlling inflation at the shortest possible horizon would have bad consequences. This policy is called "strict inflation targeting" in the literature. In practice, in an open economy, it would mean relying almost exclusively on the direct exchange rate channel to CPI inflation described above, since it has the shortest lag. For instance, any disturbance to domestic inflation that could arise from a number of different sources would be countered by attempts to move the exchange rate so as to let the domestic price of imported and exported final goods adjust to stabilize CPI inflation. This would require aggressive and volatile policy and lead to considerable volatility in interest rates and the nominal and real exchange rate, which would contribute to increased volatility of output, and surely be detrimental to welfare.

A more moderate policy, called "flexible inflation targeting" in the literature, maintains that the primary goal of monetary policy is to achieve price stability in the form of an inflation target, but also attaches some weight to stabilizing the business cycle and, consequently, stabilizing output movements around potential output. In practice and in most situations, this means taking a somewhat more gradual and more moderate approach to monetary policy, aiming to achieve the inflation target at a somewhat longer horizon (say 2-3 years) than would be technically feasible (perhaps 3-4 quarters). It also means accepting that inflation will, in the short term, deviate, sometimes quite a bit, from the inflation target. This approach also relies more on the aggregate demand channel than the direct exchange rate channel to inflation.

It is sometimes said that monetary policy, with essentially only one instrument, the instrument rate, can only have one goal, preferably low and stabile inflation. This is an oversimplification. With only one instrument, monetary policy can still have several goals, as long as these goals are weighted together into a single objective function, as discussed in greater detail in section 3.1 .

\footnotetext{
7 "Price stability" in the literature usually, somewhat inappropriately, refers to a situation with low and stable inflation, and not only to a situation with a stable price level. Throughout this paper, I only discuss inflation targeting, not price-level targeting. As discussed in Svensson [43], these are not identical. Inflation targeting makes inflation stationary, but not the price level. Imperfect control of inflation introduces shocks to the price level that are not undone. The price level becomes a random walk with drift. Even with a zero inflation target, the price level becomes a random walk. Thus, the variance of the future price level increases linearly with the forecast horizon. Price-level targeting, also with a steady increasing price-level target, would make the price level trend-stationary and the variance of the future price level would be constant. Price-level targeting has, to my knowledge, only been explicitly attempted in Sweden in the 1930s, see Berg and Jonung [9].
} 
Figure 2.1: The tradeoff between inflation variability and output-gap variability

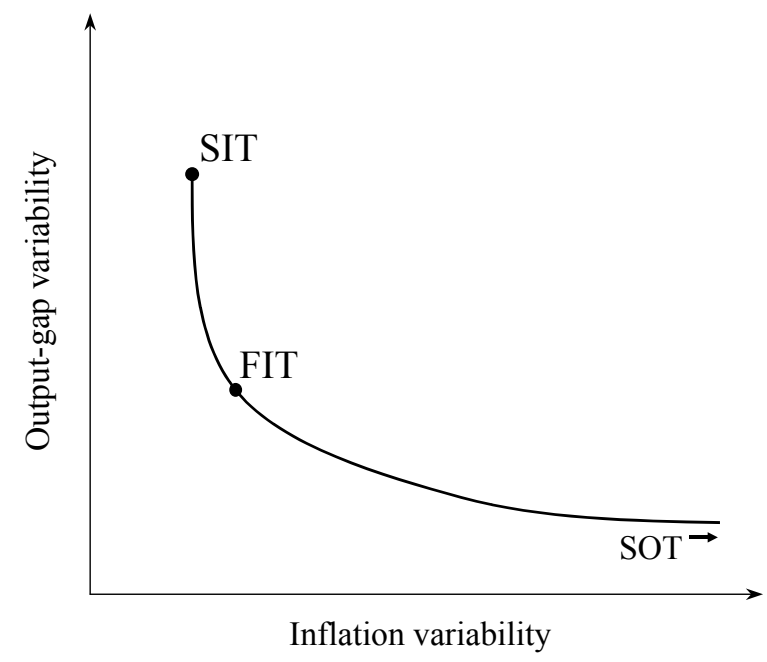

\subsubsection{The tradeoff between inflation variability and output variability}

The tradeoff between inflation variability and output-gap variability and the choice between strict and flexible inflation targeting have been discussed extensively in the monetary policy literature, for instance, in several papers presented at the Jackson Hole symposia in 1996 and 1999 (Federal Reserve Bank of Kansas City [21] and [22]). The tradeoff is often illustrated as in figure 2.1, with inflation variability around a given inflation target measured along the horizontal axis and output-gap variability measured along the vertical axis. The intersection of the axes corresponds to zero variability of inflation and the output gap, that is, inflation always equal to the inflation target and the output gap always equal to zero. Because of the complex transmission mechanism of monetary policy, unpredictable shocks, imprecise control and inevitable uncertainty, zero variability is a completely infeasible outcome. Instead, the curve, which can be called the Taylor curve, in honor of Taylor [53], where it first appeared, shows the most efficient and feasible combinations of inflation and output-gap variability that monetary policy can achieve. ${ }^{8}$ Points above and to the right of the curve correspond to inefficient monetary policy, where either inflation variability or output-gap variability, or both, could be reduced by better monetary policy. Points below and to the left of the curve correspond to outcomes that are infeasible. The point SIT corresponds to strict inflation targeting, when the central bank concentrates on stabilizing inflation without considering the consequences for output-gap

\footnotetext{
${ }^{8}$ Taylor [53] measured inflation and output-gap variability in terms of standard deviations. Given the discussion of a quadratic loss function in section 3 , it is more convenient to express variability in terms of variances.
} 
variability. It results in the lowest feasible variability of inflation but high variability of the output gap. A point such as FIT corresponds to flexible inflation targeting, where the central bank puts some weight on stabilizing output-gap variability. It leads to somewhat increased inflation variability but reduced output-gap variability. The point SOT, to the right outside the figure, corresponds to "strict output-gap targeting", when the central bank puts all weight on stabilizing the output gap. It would lead to very high inflation variability or worse, since the economy is then effectively lacking a monetary anchor.

Discussions among policymakers, experts and researchers in the monetary policy area (as reported, for instance, in [21] and [22]) have by now resulted in considerable agreement that flexible inflation targeting is the best compromise for monetary policy (see also Debelle [17]). There is also general agreement that inflation-targeting central banks in industrialized countries in practice conduct policy in this way. That is, they aim to stabilize inflation around the inflation target but also to some extent stabilize output around potential output - acknowledging that, because of the tradeoff, unpredictable shocks, uncertainty and unavoidably imperfect control, there will always remain some variability in both inflation and the output gap. The Federal Reserve System, although not being as transparent and systematic as the inflation-targeting central banks and probably having shifting goals over time, appears nevertheless to display elements of flexible inflation targeting with a relatively large weight on output-gap stabilization.

\subsubsection{Credibility and the tradeoff between inflation and the output gap}

One important mechanism for improving the tradeoff is by achieving credibility, in the sense of anchoring inflation expectations on the inflation target. With an explicit inflation target, credibility of the inflation-targeting regime can be measured as the degree of proximity between private-sector inflation expectations and the inflation target. Shocks to inflation expectations are historically an important source of variability in inflation and output, since shifts in inflation expectations have independent effects on future inflation (the direct expectations channel to domestic inflation mentioned above). ${ }^{9}$ Shifts in inflation expectations also cause additional indirect disturbances to output and inflation by affecting real interest rates and exchange rates. As a result, volatility in inflation expectations shifts the curve in figure 2.1 up and to the right and worsens the variability tradeoff. Conversely, more stable inflation expectations anchored on the inflation target improve the tradeoff, shift the curve down and to the left, and allow

\footnotetext{
${ }^{9}$ Goodfriend [25] discusses "inflation scares." Debelle [17] discusses credibility and the tradeoff between variability of inflation and the output gap.
} 
inflation variability or output-gap variability (or both) to fall. This is also because inflation expectations anchored on the inflation target create a strong tendency for actual inflation to revert to the inflation target and, everything else equal, mean that monetary policy needs to be less active. Interest rates and output need to move less to counter unfavorable movements in inflation expectations. The economy is to some extent put on autopilot. This situation is every inflation-targeting central banker's dream. Although central bankers often may seem obsessed with credibility, this obsession is for good reason.

Practical experience shows that credibility has to be earned over time. In most new inflationtargeting regimes, especially when initial inflation is high and a period of disinflation is required, inflation expectations are high and credibility is low. An idea that makes a lot of sense is that, in a new inflation-targeting regime, the central bank puts more weight on reducing and stabilizing inflation and is a less flexible inflation targeter, in order to more quickly achieve credibility. The cost would be more output-gap variability in the beginning of the regime. The benefit would be an improved tradeoff and lower variability of both inflation and the output gap later on, when credibility has improved and the central bank can afford to be a more flexible inflation targeter.

This can be illustrated in terms of figure 2.1 in the following way: Suppose, because of low initial credibility, that the economy initially is at a point northeast of point FIT, with higher variability of both inflation and the output-gap. This initial point would be on an initial tradeoff curve located to the northeast of the curve through points FIT and SIT. Suppose the central bank implements strict inflation targeting. This would correspond to a move northwest along the initial tradeoff curve. If credibility improves, the tradeoff curve would shift to the southwest, to the curve through points FIT and SIT. The economy would then be at point SIT. If the central bank then implements flexible inflation targeting, the economy would move to point FIT. Compared to the initial situation, the economy would benefit from lower variability of both inflation and the output gap.

\subsubsection{Independent stabilization of interest rates and the exchange rate}

A separate issue is the desirability and feasibility of independent stabilization of interest rates and the exchange rate. It is certainly possible for the central bank to stabilize either the interest rate or the exchange rate somewhat, at the cost of increased variability of inflation and/or the output gap. Is it desirable for the central bank to do so? Except in situations of financial fragility with concerns about the stability of the financial and payment system (to be 
discussed in section 4), I find it difficult to see good reasons for such stabilization at the cost of increased inflation and output-gap variability (see further discussion in section 3.1). In practice, flexible inflation targeting, with a longer horizon to meet the inflation target and concern for output-gap variability, will normally mean a more gradual approach and a less activist policy and hence reduced interest rate variability. Since interest rate changes lead to exchange rate changes, everything else equal, this also reduces exchange rate variability. Increased credibility and increasingly stable inflation expectations will reduce a major source of shocks to both interest rates and exchange rates. Thus, successful and credible flexible inflation targeting is likely to contribute to less variability of interest rates and exchange rates. However, exchange rates are by nature volatile asset prices and are affected by a number of shocks beyond inflation expectations and interest rate changes. Such shocks will continue to cause unavoidable exchange rate variability.

\subsection{Summary}

In the long term, monetary policy can only control nominal variables such as inflation and the nominal exchange rate. It cannot increase the average level or the growth rate of real variables such as GDP and employment, or affect the average level of the real exchange rate. At best it can reduce the variability of real variables somewhat. In the short and medium term, monetary policy has effects on both nominal and real variables. However, the complex transmission mechanism of monetary policy, varying lags and strength of the effects through different channels, unpredictable shocks and inherent uncertainty combine to prevent any fine-tuning. There is general international support for a regime of flexible inflation targeting, where inflation is stabilized around a low inflation target in the medium term (rather than at the shortest possible horizon) and a gradual and measured policy response avoids creating unnecessary variability in the real economy. This still leaves some ambiguity about the precise relative weight on output-gap stabilization relative to inflation stabilization. I will argue in the next section that this remaining ambiguity can be eliminated, and that it is a good thing to do so.

\section{How to achieve the optimal compromise between inflation stability and output-gap stability}

How can a central bank achieve the optimal compromise between inflation stabilization and output-gap stabilization, while maintaining long-run price stability in the sense of an average 
inflation equal to the inflation target? I believe this can be done by refined flexible inflation targeting in the following way:

1. The central bank first formulates, announces and motivates an explicit loss function for inflation deviations from the inflation target and output deviations from potential output. This loss function is effective for several years. (Although this idea of an explicit loss function may appear quite shocking to some central bankers, as we shall see, we are only talking about one more number than the inflation target.)

2. Before each major monetary-policy decision (say about every quarter), conditional on the central bank's view of the transmission mechanism, its estimate of the current state of the economy, and its judgment about relevant circumstances and shocks, the central bank constructs a set of conditional (mean) forecasts, projections, of the target variables for alternative instrument-rate paths, thereby tracing out the feasible set of alternative inflation and output-gap projections.

3. The central bank then selects the projections of inflation and the output gap in the feasible set that minimizes the loss function and thereby best fulfill the objectives. These projections will return inflation to the inflation target and output to potential output at the appropriate pace, thereby achieving the long-run inflation target as well as the best compromise between any short-run deviations of inflation from the inflation target and output deviations from potential output.

4. The central bank announces the optimal projection of the target variables and the corresponding projection of the instrument-rate path (normally time-varying), and publishes and explains the analysis that results in these projections. These projections then become the central bank's best unconditional forecast of future inflation, output gap and instrument rate ("unconditional" forecast in the standard sense of incorporating all relevant information, including the central bank's best prediction of its future interest-rate setting).

5. The central bank then sets the current instrument rate in line with the optimal instrument projection, and continues to do so until the next major monetary-policy decision.

6. At the time of the next monetary-policy decision, the central bank repeats step 2-5, taking into account the new information that has arrived, its new estimate of the current state 
of the economy, and its new judgment about relevant circumstances and shocks.

It is worth emphasizing that the above is not a mechanical procedure and that it does not rely on models only. Instead it allows for considerable judgment and discretion in constructing the projections. It is an example of the "constrained discretion" that according to Bernanke and Mishkin [13] characterizes inflation targeting. It has much in common with current best international practice of inflation targeting, in New Zealand, the U.K. and Sweden. ${ }^{10}$ It is "refined" flexible inflation targeting in that it goes beyond current best practice in making precise and explicit (rather than implicit) the real stabilization objective and in formulating an explicit loss function, and in using this loss function to select the optimal projections of inflation and the output gap. It is similar to the practice in New Zealand of publishing a time-varying projection for the interest rate, but it goes beyond the practice in Sweden and the U.K. of relying on and publishing projections of inflation and output conditional on an unchanged interest rate.

\subsection{Specifying an explicit loss function}

An essential element in achieving the best compromise between inflation and output-gap stabilization is obviously to specify what is meant by the best compromise. There are several advantages to being explicit and transparent and avoiding ambiguity and obfuscation about the loss function: Explicit objectives improve the focus inside the central bank on achieving the goals, provide for more consistent policy, and allow more precise internal evaluation of past policy. Transparent communication of those objectives allows more precise and relevant external monitoring and evaluation of central-bank policy, thereby improving the incentives for the central bank to achieve the stated objectives. Furthermore, it allows scrutiny of and debate about the objectives themselves, an essential aspect of a democracy. ${ }^{11}$

Inflation-targeting central banks, although being strong advocates of transparency in monetary policy, have so far avoided completely specifying their loss function. However, without such specification, the precise monetary-policy objectives under inflation targeting are still open to

\footnotetext{
${ }^{10}$ Some readers may ask why I do not include Canada as a country with best international practice of inflation targeting. After all, Canada was the second country after New Zealand to introduce an explicit inflation target, and Bank of Canada has considerable accumulated experience and has been quite influential in advising other central banks introducing inflation targeting. The reason is that Bank of Canada does not yet live up to best international practice when it comes to transparency, since it does not publish a detailed internal inflation forecasts. When that occurs, I will be very pleased to list Bank of Canada as one of the best-international-practice inflation targeters. However, the competition at the top may be stiffening: Bank of Norway, for instance, is a competent and enthusiastic newcomer to the inflation-targeting camp, see Svensson, Houg, Solheim and Steigum [51].

11 Goodhart [26, p. 173] expresses some scepticism about feasibility of both establishing and minimizing an explicit loss function for monetary policy. I argue in some detail against that scepticism in Svensson [49], on which paper this section builds.
} 
interpretation and continue to suffer from a lack of transparency. Especially, how much weight is put on stabilizing the real economy relative to stabilizing inflation around the inflation target? Indeed, the objectives can be misunderstood. For instance, Meyer [35], although arguing strongly in favor of a numerical inflation target, interprets the inflation-targeting regimes in New Zealand, Canada and the U.K. as having a "hierarchical" mandate for price stability and contrasts this with a "dual" mandate (which he favors) in Australia and the U.S. Although, as explained below, I believe this distinction between a hierarchical and dual mandate is a misunderstanding of the nature of flexible inflation targeting (and I argue in Svensson [45] that New Zealand is currently a prime example of flexible inflation targeting), as long as inflation targeting central banks do not announce a precise loss function for monetary policy, misunderstandings of the precise objectives are invited.

The objectives corresponding to flexible inflation targeting can be described precisely by a quadratic period loss function

$$
L_{t}=\left(\pi_{t}-\pi^{*}\right)^{2}+\lambda\left(y_{t}-\bar{y}_{t}\right)^{2}
$$

where $\pi_{t}$ and $y_{t}$ denote inflation and output in period $t$, respectively, $\pi^{*}$ is the inflation target, $\bar{y}_{t}$ is potential output, $y_{t}-\bar{y}_{t}$ is consequently the output gap, and $\lambda>0$ is the relative weight on output-gap stabilization. Thus, inflation and output are the "target variables," that is, the variables that enter the loss function. The corresponding "target levels" are $\pi^{*}$ and $\bar{y}_{t}$, respectively. (Equivalently, we can say that inflation and the output gap are the target variables, with the target levels $\pi^{*}$ and 0 , respectively.)

Because of the lags in the effect of monetary policy actions on inflation and output, the central bank has to be forward-looking and consider the effects of current monetary-policy actions on future inflation and output gap. Furthermore, because of the unavoidable uncertainty and imperfect control, the objectives have to be expressed in terms of expected future losses. Also, potential output, $\bar{y}_{t}$, is an unobservable variable that has to estimated. This is achieved by considering an intertemporal loss function in each period $t$ in the form of expected discounted future losses,

$$
\mathcal{L}_{t}=(1-\delta) \mathrm{E}_{t} \sum_{\tau=0}^{\infty} \delta^{\tau} L_{t+\tau},
$$

where $\delta(0<\delta<1)$ is a discount factor and $\mathrm{E}_{t}$ denotes expectations (estimations) conditional on information available in period $t .^{12}$

\footnotetext{
${ }^{12}$ The scaling by $1-\delta$ of the expected sum of discounted future losses is practical, since it implies that the
} 
The target level for the output gap is thus equal to potential output. There is general agreement that inflation-targeting central banks do normally not have overambitious output targets, that is, exceeding potential output. Thus, discretionary optimization does not result in average inflation bias, counter to the case in the standard Kydland-Prescott-Barro-Gordon setup. Since the inflation target is subject to choice but the output target is given by (estimated) potential output (as discussed above in section 2.2, having an output target for monetary policy different from potential output makes no sense), there is an asymmetry between the inflation target and the output target, consistent with the inflation target being the "primary objective" and a "hierarchical" mandate. On the other hand, once the inflation target has been determined, the objective is to minimize an expected weighted sum of squared inflation deviations from the inflation target and squared output deviations from potential output. In this sense, flexible inflation targeting can be interpreted as a "dual" mandate. Thus, the hierarchical mandate applies to the average level objectives, whereas the dual mandate applies to the variability objectives. Thus, flexible inflation targeting can be interpreted as having both a hierarchical and a dual mandate, and no conflict need arise between them.

The intertemporal loss function has only three parameters: $\pi^{*}, \lambda$ and $\delta$. For an inflationtargeting central bank, there is a specified inflation target (a point target or the midpoint of a range), $\pi^{*}$, and a specified index measuring inflation. The inflation target can be determined by the government, as in the U.K., specified in an agreement between the government and the central bank, as in New Zealand, or determined by the central bank as an interpretation of legislation specifying "price stability" as the target for monetary policy, as in Sweden. Regarding the remaining two parameters, the discount factor and the relative weight, $\delta$ and $\lambda$, the discount factor is for all practical purposes likely to be very close to one, especially when the period is a quarter. Interestingly, when the discount factor is close to unity (and the intertemporal loss function is scaled by $1-\delta$ as in (3.2)), the intertemporal loss function is approximately equal to the weighted sum of the unconditional variances of inflation and the output gap,

$$
\lim _{\delta \rightarrow 1} \mathcal{L}_{t}=\operatorname{Var}\left[\pi_{t}\right]+\lambda \operatorname{Var}\left[y_{t}-\bar{y}_{t}\right]
$$

(when the unconditional means of inflation and the output gap equal the inflation target and zero, respectively: $\mathrm{E}\left[\pi_{t}\right]=\pi^{*}$ and $\left.\mathrm{E}\left[y_{t}-\bar{y}_{t}\right]=0\right) .{ }^{13}$ As mentioned, flexible inflation targeting

sum of the scaled discount factors is unity, $\Sigma_{\tau=0}^{\infty}(1-\delta) \delta^{\tau}=1$. This implies that the sum is of the same order of magnitude and in the same units as period losses.

${ }^{13}$ However, a fine point to remember is that, since (3.3) does not allow derivatives with respect to inflation and output gap in a particular (future) period, when such derivatives are needed, they must be computed before the 
corresponds to a positive weight on output gap stabilization, $\lambda>0$. Strict inflation targeting would be the unrealistic case of a zero weight on output-gap stabilization, $\lambda=0$. In figure 2.1 , with the variance of inflation and the output gap along the axes, the indifference curves corresponding the loss function (3.3) then corresponds to negatively sloped straight lines, with the slope of the line being the reciprocal of $\lambda$. Thus, strict inflation targeting $(\lambda=0,1 / \lambda=\infty)$ corresponds to vertical indifference lines, making the point SIT optimal. Strict output-gap targeting $(\lambda=\infty, 1 / \lambda=0)$ corresponds to horizontal indifference lines, making the point SOT optimal. Flexible inflation targeting $(\lambda>0,1 / \lambda>0)$ corresponds to negatively sloped indifference lines, making a point like FIT optimal.

Thus, there is effectively actually only one parameter, $\lambda$, that needs to be determined beyond the inflation target for the loss function to be completely explicit. Thus, although some (conservative?) central bankers may be shocked by the idea of determining and announcing an explicit intertemporal loss function, we are only talking about one more number than the inflation target. Furthermore, that number has a very simple interpretation, the relative weight on output-gap variability relative to inflation variability in the loss function. Thus, a $\lambda$ equal one means that the central banker dislikes output-gap variability to the same extent as he or she dislikes inflation variability. A $\lambda$ equal to a half means that the central banker dislikes output-gap variability by a half relative to the dislike of inflation variability.

For the normal case of central banks where decisions are made by a committee, which we generically call the Monetary Policy Committee (MPC), majority voting is a natural mechanism for aggregating decisions and preferences (New Zealand is the exception among industrialized countries with a single decision maker for monetary policy). Since under majority voting, the median wins, the MPC's aggregate $\lambda$ would be the median of the MPC members' individual $\lambda \mathrm{s} .{ }^{14}$ Of course, the MPC members may need some introspection and assistance in deciding what their individually favored $\lambda$ is, for instance, by ranking a few potential outcomes. Fortunately, as noted above, the interpretation of $\lambda$ is very simple, though. The members simply need to make up their mind about what their relative dislike of output-gap variability relative to inflation variability. (That is, $\lambda$ is the marginal rate of substitution of inflation variance for output-gap variance.)

limit is calculated. Along the same line of reasoning, objectives in the form of expected discounted future losses like (3.2) with (3.1) are more operational than in the form (3.3), since the former form can be used to evaluate single projections of inflation and the output gap (see further discussion below).

${ }^{14}$ Let median $(v)$ denote the median of the elements of the vector $v$. For an MPC with $J$ members, let $\lambda_{j}$ denote the individually preferred relative weight of member $j, j=1, \ldots, J$. Then the MPC's aggregate relative weight, $\bar{\lambda}$, will simply be given by $\bar{\lambda}=\operatorname{median}\left(\lambda_{1}, \lambda_{2}, \ldots, \lambda_{J}\right)$. 
Since potential output is an unobservable variable that needs to be estimated, the members also need to decide on what concept of potential output to be used and what is the best estimate of potential output each time. Again, majority voting will result in the MPC's concept and estimate of potential output being the medians of the MPC members' individual concepts and estimates. (Of course, the MPC handles numerous such decisions on a number of variables, especially those MPCs who are more actively involved in the projection process of the bank, so such decisions are actually commonplace and not at all exotic.)

Indeed, compared to many other real-world committee decisions, this aggregation procedure into an MPC loss function is quite simple. After the MPC's loss function has been specified, the members could agree to jointly apply that loss function rather than their individual ones. Such an aggregate loss function can be seen as the majority's operational interpretation of government instructions like the Chancellor's letter to Bank of England or legislation like the Swedish Riksbank Act or the U.S. Federal Reserve Act. ${ }^{15} 16$

Regarding additional objectives, like interest-rate stabilization and/or smoothing (corresponding to additional terms $\left.\lambda_{i}\left(i_{t}-i^{*}\right)^{2}+\lambda_{\Delta i}\left(i_{t}-i_{t-1}\right)^{2}\right)$, my own view is that there are no good reasons why they would enter a loss function corresponding to inflation targeting (this is discussed in some detail in Svensson [50, section 5.6]). I believe the observed serial correlation in actual instrument-rate settings can be explained by other circumstances (gradual updating of

${ }^{15}$ Although some might argue (and even favor) that MPCs, especially the Federal Open Market Committee of the Federal Reserve System, work by members having different individual loss functions and voting according to those individual loss functions, I find that situation of different unknown loss functions inconsistent with a reasonable degree of transparency.

${ }^{16}$ Gaspar and Smets [24] discuss several cases when the central bank achieves better results, from the point of view of society, if it has a relative weight on output-gap stabilization, $\lambda$, that is less than society's, what is called "weight-conservativeness" in Svensson [42]. The classic argument for weight-conservativeness is in Rogoff [40], where it reduces average inflation bias under discretion. This, of course, presupposes that the central bank has an output target that exceeds potential output (an output-gap target that is positive), so there is an average inflation bias in the first place. Average inflation bias seems to have more or less vanished from practical monetary policy. I believe the best explanation for this is rather that central banks have become "output-conservative," in the sense of having an output-gap target equal to zero, as discussed above for inflation-targeting central banks. This explanation is also consistent with the data, since countries with lower inflation do not have higher output variability (higher output variability is a prediction of weight-conservativeness). Gaspar and Smets discuss more recent arguments for weight-conservativeness, for instance, that it may reduce the "stabilization bias" that results under discretion in more complex models than the original Kydland-Prescott-Barro-Gordon model. However, stabilization bias is quite model-dependent, and it need not always go in the same direction. Furthermore, a commitment to an optimal targeting rule, as in Svensson and Woodford [52], is a better way to avoid stabilization bias, and the optimal targeting rule remains quite simple in the models considered by Gaspar and Smets. Ehrmann and Smets [20] shows that, in the (very realistic) situation where there is uncertainty about potential output, a weight-conservative central bank under discretion would only marginally improve social welfare. Even then, a commitment to the relatively simple optimal targeting rule would be best. Orphanides and Williams [37] consider a situation with simple learning and expectation formation by the private sector, in the form of the running of simple regressions of current inflation on lagged inflation, and show that weight-conservativeness has the good effect of stabilizing inflation expectations. However, this is a very primitive form of learning, and transparent inflation-targeting central banks affect inflation expectations much more directly via published inflation forecasts and by explaining how monetary policy works. On balance, I am not convinced by the various arguments presented in favor of weight-conservativeness, and I believe that the MPC should not try to be weight-conservative relative to society, except possibly when a new inflation-targeting regime needs to establish credibility, as discussed in section 2 . 
unobservable state of the economy, implicit history-dependence corresponding to a commitment to "continuity and predictability" or optimal policy in a time-less perspective, etc.). However, if MPC members interpret the instruction from the government or the legislation as implying such additional objectives, they could vote on how to specify them and make the corresponding terms in the loss function explicit. Furthermore, as discussed in section 4, I believe that additional objectives like financial stability and a functioning payment system can be best handled as constraints that do not bind under normal circumstances. In exceptional circumstances, when they do bind, this could be explicitly announced and entered into the motivation for policy decisions. Under normal circumstances, the constraints can be disregarded and do not affect policy.

The period loss function (3.1) is a symmetric loss function (the value for $\pi_{t}-\pi^{*}$ is the same as the value for $-\left(\pi_{t}-\pi^{*}\right)$, etc. $)$. Some researchers have argued that asymmetric preferences are relevant in monetary policy and also examined their implications. This would require a more complex loss function. Put differently, a second-order approximation is not enough, and higherorder terms are needed. I find a symmetric loss function for monetary policy very intuitive, especially since these days not only too high inflation but also too low inflation is considered undesirable, due to the risk of falling into liquidity traps and deflationary spirals (see section 5). Furthermore, more complex loss functions and more complicated tradeoffs may be too sophisticated to be both operational and sufficiently verifiable for reasonable accountability. ${ }^{17}$

\subsection{Forecast targeting}

Once the central bank has specified its precise loss function, how does it conduct policy so as to actually minimize it? I believe "forecast targeting" is the way to do it.

As discussed in section 2, monetary policy affects the economy with considerable lags. Current inflation and output are, to a large extent, determined by previous decisions of firms and households. Normally, current monetary-policy actions can only affect the future levels of inflation and the output gap, in practice with substantial lags and with the total effects spread out over several quarters. This makes forecasts of the target variables crucial in practical monetary policy. By "forecast targeting," I mean using forecasts of the target variables effectively as intermediate target variables, as in King's [28] early characterization of inflation targeting. This

\footnotetext{
17 Nobay and Peel [36], ali-Nowaihi and Stracca [2] and Ruge-Mercia [41] examine alternative asymmetric monetary-policy loss functions. Asymmetric loss functions are frequently motivated from a descriptive rather than prescriptive point of view, for instance, corresponding to observed deviations from rational behavior. I believe an informed and competent MPC deciding on the appropriate loss function should approach the issue from a prescriptive point of view and select the most appropriate and rational loss function.
} 
means minimizing a loss function where forecasts enter as arguments. ${ }^{18}$

Let us assume that the transmission mechanism is approximately linear, in the sense that the future target variables depend linearly on the current state of the economy and the instrument rate. Furthermore, assume that any uncertainty and any deviation from the simple models enter additively. Finally, let the intertemporal loss function be quadratic, as above in (3.1). It is then a standard result in optimal-control theory that so-called certainty-equivalence applies, and that optimal policy need only focus on conditional mean forecasts of the future target variables, that is, mean forecasts conditional on the central bank's current information and a particular future path for the instrument rate. Since this implies treating the forecasts as (intermediate) target variables (that is, putting forecasts of the target variables in the loss function), the procedure can be called "forecast targeting." 1920

Let me be more specific. Let $i^{t}=\left\{i_{t+\tau, t}\right\}_{\tau=0}^{\infty}$ denote an instrument-rate plan in period $t$ (where $i_{t+\tau, t}$ denotes the planned instrument level for period $t+\tau, \tau \geq 0$ ). Conditional on the central bank's information in period $t$, denoted $I_{t}$ (including its view of the transmission mechanism, etc.), and its "judgment," denoted $z^{t}$, and conditional on alternative instrumentrate plans $i^{t}$, consider alternative (mean) forecasts for inflation, $\pi^{t}=\left\{\pi_{t+\tau, t}\right\}_{\tau=0}^{\infty}$, output, $y^{t}=$ $\left\{y_{t+\tau, t}\right\}_{\tau=0}^{\infty}$, potential output, $\bar{y}^{t}=\left\{\bar{y}_{t+\tau, t}\right\}_{\tau=0}^{\infty}$, and hence for the output gap, $y^{t}-\bar{y}^{t}=\left\{y_{t+\tau, t}-\right.$ $\left.\bar{y}_{t+\tau, t}\right\}_{\tau=0}^{\infty}$. That is, $\pi_{t+\tau, t}=\mathrm{E}\left[\pi_{t+\tau} \mid i^{t}, I_{t}, z^{t}\right]$, the expectation of inflation in period $t+\tau$, conditional on the instrument path $i^{t}$, the central bank's information $I_{t}$ and its judgment $z^{t}$, etc. Furthermore, consider the intertemporal loss function in period $t$ applied to the forecasts of the target variables, that is, when the forecasts are substituted into the intertemporal loss

\footnotetext{
${ }^{18}$ Meltzer [33], writing in 1986, emphasized the magnitude of forecast errors and expressed severe doubts about discretionary policy based on forecasts and judgment. Evidence from the last decade undoubtedly puts policy, that is based on forecasts and judgment but, in addition, is constrained by a more explicit objective and explained in a transparent way, in a much better light.

${ }^{19}$ In cases when the assumptions of a linear model and quadratic loss function are not fulfilled, as discussed in Svensson [46] and [50], one can still apply "distribution forecast targeting," where the forecasts are explicit probability distributions and the intertemporal loss function is the explicit or implicit integral over those distributions.

20 Bank of England and the Riksbank do not publish graphs of mean (that is, probability-weighted average) forecasts in their Inflation Reports but rather of mode (that is, maximum probability) forecasts, with "fan charts" and confidence intervals illustrating the probability distribution. Since the mode forecast has no special policy relevance (unless the loss function is of the rather bizarre all-or-nothing kind, see Wallis [55] and Vickers [54]), it would make more sense to plot graphs of mean forecasts. The mean and the mode are usually not that different, though, since they (for a uni-modal probability distribution) differ only when the probability distribution is asymmetric and the distribution is usually relatively symmetric. When the probability distribution is asymmetric, there is usually some discussion in their Inflation Reports of the relative size of "upward" and "downward" risks, which can perhaps be interpreted as a modification of the mode forecast towards the mean. If the mean would be plotted instead, no such modification would be needed, and the fan chart can be interpreted as just displaying the uncertainty of the forecast around the mean. This would be a more transparent way of communicating, I believe.
} 
function (3.2) with (3.1),

$$
\mathcal{L}_{t}=(1-\delta) \sum_{\tau=0}^{\infty} \delta^{\tau}\left[\left(\pi_{t+\tau, t}-\pi^{*}\right)^{2}+\lambda\left(y_{t+\tau, t}-\bar{y}_{t+\tau, t}\right)^{2}\right] .
$$

Each period $t$, conditional on the central bank's forecasting model, information $I_{t}$ and judgment $z^{t}$, the bank then finds the combination of feasible forecasts $\pi^{t}$ and $y^{t}-\bar{y}^{t}$ and instrumentrate plan $i^{t}$ that minimizes (3.4), and then makes the current instrument-rate decision according to the current optimal instrument-rate plan. The process will result in an endogenous reaction function for the current instrument-rate decision, $i_{t}$, a function $i_{t}=F\left(I_{t}, z^{t}\right)$ of the central bank's information and judgment in period $t$. This reaction function need not be specified explicitly, however, and it need not be followed mechanically. (This is fortunate, since even in very simple problems, this reaction function is often quite complicated.) ${ }^{21}$

So which prices and quantities and other information available to the central bank would it then respond to under this procedure? The answer is the prices, quantities and other information that have an effect on the projections. Put differently, the information available to the central bank is filtered through the projections, and only the information that has an effect on the projection is worth responding to. Thus, the central bank may respond to current inflation, output gap and other important variables, but only to the extent that these have an effect on the projections. To repeat, the implicit reaction function, $i_{t}=F\left(I_{t}, z^{t}\right)$, will be a very complex function of the central banks information and judgment, but fortunately the reaction function can remain implicit and the central bank need not face the impossible task of making this reaction function explicit. Thus, forecast targeting is very different from a commitment to a simple instrument rule, like the Taylor rule, as discussed in more detail in Svensson [50].

More generally, since the central bank will only respond and adjust its instrument rate to information that affect the projections sufficiently far, a large share of the new information will not be responded, because it has no impact on the projections. Furthermore, apparently sizeable pieces of information may have still have quite small impacts on the projections and therefore lead to a very small response. Thus, there is no fine-tuning in the sense that there is not a response to every incoming piece of information.

Forecast targeting requires that the central bank has a view of what the policy multipliers

\footnotetext{
${ }^{21}$ For simplicity I here abstract from a time-consistency problem that arises with models with forward-looking variables. Even in the absence of an average inflation bias, this time-consistency problem results in "stabilization bias" (non-optimal coefficients in the implicit reaction function) and a lack of history-dependence. The magnitude of the problem may be small in realistic models with relatively strong backward-looking elements. The nature of the problem and possible solutions, including "a commitment to continuity and predictability" or a commitment to an optimal targeting rule are discussed in Svensson and Woodford [52] and Svensson [50].
} 
are, that is, how instrument-rate adjustments affect the conditional inflation and output-gap forecasts. But it does not imply that forecasts must be exclusively model-based. Instead, it allows for extra-model information and judgmental adjustments, as well as very partial information about the current state of the economy. It basically allows for any information that is relevant for the inflation and output-gap forecasts.

How would the central bank find the optimal projections and instrument-rate plan? One possibility is that, conditional on the information $I_{t}$ and the judgment $z^{t}$, the central-bank staff generates a set of alternative projections for a set of alternative instrument-rate plans. This way, the staff constructs the transformation set of feasible projections and instrument-rate plans. The MPC would then select the combination of projections that "looks best," in the sense of achieving the best compromise between stabilizing the inflation gap and stabilizing the output gap, that is, minimizes (3.4). This can be done informally with visual inspection of the projections. It can also be done more formally with the explicit loss function, since then the loss for each combination of inflation and output-gap projections can easily be calculated numerically. (To do the latter is one of my suggestions to the Reserve Bank of New Zealand in Svensson [45].)

Another possibility is that the MPC determines a "targeting rule," a condition that the projections of the target variables must fulfill. Conditional on the information and the judgment, the staff then has to generate the combination of projections of the target variables that fulfills the targeting rule and the corresponding instrument-rate plan. The Bank of England and the Riksbank have formulated a simple targeting rule to guide policy, which can be expressed approximately as "set the instrument-rate so a constant-interest-rate inflation forecast about two years ahead is on target" (Goodhart [26] and Heikensten [27]). ${ }^{22}$ With the period being a quarter, this targeting rule can be written

$$
\pi_{t+8, t}=\pi^{*}
$$

with the understanding that the inflation forecast is constructed under the assumption of a constant interest rate. Although this targeting rule is both simple and operational, it is not likely to be optimal.

\footnotetext{
${ }^{22}$ As Goodhart [26, p. 177] puts it: "When I was a member of the MPC I thought that I was trying, at each forecast round, to set the level of interest rates so that, without the need for future rate changes, prospective (forecast) inflation would on average equal the target at the policy horizon. This was, I thought, what the exercises was supposed to be."

Nevertheless, Bank of England (2000, p. 67) states that "[h]owever, there is no mechanical link between the projected level of inflation in two years time based on constant interest rates and the appropriate current setting of monetary policy."
} 
As is discussed in some detail in Svensson [50] and [49], an optimal targeting rule instead expresses the equality of the marginal rates of transformation (in the transmission mechanism) and substitution (in the loss function) between the target variables in an operational way. In the popular New Keynesian model with a forward-looking Phillips curve, this targeting rule has the simple form

$$
\pi_{t+\tau, t}-\pi^{*}=-\frac{\lambda}{\kappa}\left[\left(y_{t+\tau, t}-\bar{y}_{t+\tau, t}\right)-\left(y_{t+\tau-1, t}-\bar{y}_{t+\tau-1, t}\right)\right],
$$

where $\lambda$ is the relative weight on output-gap stabilization in the loss function and $\kappa$ is the slope of the short-run Phillips curve. That is, the targeting rule says that the deviation of the inflation projection from the inflation target should be negatively proportional to the projection of the output-gap change, where the proportionality factor is the ration between the relative weight on output-gap stabilization and the slope of the short-run Phillips curve.

As discussed more thoroughly in Svensson [50], the optimal targeting rule has the attractive properties that it only depends on the marginal tradeoffs between the target variables. Therefore, it only depends on the loss function (via the relative weight $\lambda$ ) and the form of the aggregate supply/Phillips curve (via the slope of the short-run Phillips curve, $\kappa$ ). In particular, judgment does not enter explicitly in the optimal targeting rule. Still, judgment will be incorporated in the construction of the forecasts. Furthermore, the targeting rule solves the time-consistency problem, so that it corresponds to the full commitment equilibrium "in a time-less perspective" (Woodford [56] and Svensson and Woodford [52]). Thus, it causes no "stabilization bias" and it has the appropriate "history-dependence" that is a characteristic of the fully optimal solution when there are forward-looking variables.

We note that the intertemporal loss function (3.4) and the optimal targeting rule (3.5) refer to the whole future path of the inflation and output-gap projections. It does not refer to a specific horizon, like the two-year horizon emphasized by Bank of England and the Riksbank at which the inflation forecast shall be on target. Indeed, the focus on a specific horizon is not supported by this approach. ${ }^{23} 24$

\footnotetext{
${ }^{23}$ Furthermore, as discussed in Svensson [47], inflation-forecast targeting, either in the general form of minimizing a loss function over forecasts or in the specific form of fulfilling a targeting rule is generally not the same thing as implementing a "forecast-based" instrument rule, as

$$
i_{t}=\gamma\left(\pi_{t+T, t}-\pi^{*}\right),
$$

where the instrument rate responds to a $T$-period-ahead inflation forecast, or the variants thereof that originated in Bank of Canada's Quarterly Projection Model and are examined by, for instance, Batini and Haldane [6], McCallum and Nelson [32] and Batini and Nelson [8].

${ }^{24}$ Batini and Nelson [8] discuss two very different definitions of the policy horizon in monetary policy, calling
} 


\subsection{Time-varying instrument-rate paths}

The above decision-making process centers on finding the optimal combination of inflation and output-gap projections and instrument-rate plan, the $\left(\pi^{t}, x^{t}, i^{t}\right)$ that minimizes the intertemporal loss function or fulfill the targeting rule, conditional on current information, including the view of the transmission mechanism, and current judgement. There is no reference to the forecasts conditional on an unchanged instrument rate that are used by Bank of England and the Riksbank (and by the Eurosystem as well). Thus, the process involves the MPC agreeing on forecasts and instrument-rate plans that normally are time-varying.

One argument against using time-varying interest-rate paths has been formulated by Goodhart [26, p.172-173]: "[I]t is hard to see how a committee could ever reach a majority for any particular time path. A great advantage of restricting the choice to what to do now, this month, is that it makes the decision relatively simple, even stark. Given the difficulties involved already in achieving majority agreement in the MPC on this simple decision, the idea of trying to choose a complete time path by discretionary choice seems entirely fanciful and counter-productive."

I am not convinced by this argument. MPCs are already agreeing on time-varying inflation and output forecasts, so agreeing on a time-path does not seem to be impossible at all. It is true that there are general problems aggregating preferences in a MPC and that it is easiest to vote about a one-dimensional issue, like an instrument-rate level (or the parameter $\lambda$ as discussed above). In particular, majority voting will lead to the median-voter outcome, in which the median of the MPC members' individually favored levels of the instrument-rate will be chosen.

Along these lines, I have a simple proposal for how an MPC can reach agreement on an instrument-rate plan: Let each MPC member plot his/her preferred instrument-rate plan in the same graph with the future periods (quarters) on the horizontal axis and the instrument rate on the vertical axis (the resulting set of curves might cross each other at several future dates). Form the MPC's aggregate instrument-rate plan by taking the median of the instrument rates for each future quarter. ${ }^{25}$ This median instrument-rate plan can be seen as the result of a majority vote in a particular voting procedure ${ }^{26}$ Conditional on this instrument-rate plan, agree

them the "optimal policy horizon" and the "optimal feedback horizon." The former refers to the horizon at which inflation reaches the target after a shock away from the target; the latter refers to the optimal horizon $T$ for a forecast in a forecast-based instrument rule. In general, there is no specific relation between the leads of inflation that appear in the optimal specific targeting rule and the leads that correspond to these optimal-horizon definitions. Put differently, there is no specific "optimal horizon."

${ }^{25}$ Let each member $j, j=1, \ldots, J$, of the MPC individually prefer the instrument-rate plan $i^{t j} \equiv$ $\left\{i_{t+\tau, t}^{j}\right\}_{\tau=0}^{\infty}$ in period $t$. Then the MPC's aggregate instrument-rate plan, $\bar{\imath}^{t} \equiv\left\{\bar{\imath}_{t+\tau, t}\right\}_{\tau=0}^{\infty}$, fulfills $\bar{\imath}_{t+\tau, t}=$ $\operatorname{median}\left(i_{t+\tau, t}^{1}, i_{t+\tau, t}^{2}, \ldots, i_{t+\tau, t}^{J}\right)$ for all $\tau \geq 0$.

26 The proposal can be seen as a mechanism for aggregating preferences that avoids the so-called Condorcet 
on the inflation and output-gap projection. If necessary, let each MPC plot his/her projection of inflation and the output gap, and pick the median outcome of these. If these do not look good, let each MPC member consider new individual instrument-rate plans, and then take the median of these. I would be surprised if this procedure does not converge very quickly.

The observant reader will realize that a median instrument-rate plan and inflation and output-gap projections picked this way need not be entirely consistent, in the sense that the median inflation and output-gap projections may include segments that correspond to instrumentrate plans differing from the median instrument-rate plan. Still, I believe any such inconsistency must be a minor problem, and a final round of adjustments in the MPC's decision may explicitly aim to reduce or eliminate any such inconsistency. Furthermore, the staff of the central bank will be able to spot any inconsistencies and assist the MPC in eliminating them.

The resulting instrument-rate plan and inflation and output-gap projections would then be seen as reflecting the majority view of the MPC. Dissenters then have the option to explicitly dissent in the minutes of the meeting. The general setup with the MPC's decision reflecting the majority view and the possibility of dissent is already used by the Riksbank's Executive Board. I think it is more logical and easy to understand than the idea of the "best collective judgment" used by Bank of England's MPC (see Kohn [29]).

The advantages in using the optimal inflation and output-gap projections and instrument plans (rather than inflation and output-gap projections conditional on a constant interest rate) seem overwhelming to me: (1) This combination of projections and instrument plan are the best forecasts of inflation, the output gap and the instrument rate conditional on the information available and the central bank's judgment. This means that it makes sense to compare these to private-sector forecasts, and to actual outcomes. (2) It is longer real interest rates rather than the short real rate that affects aggregate demand. Therefore, monetary policy is more effective if it impacts the whole term structure of interest rates. The best way to do this is to announce the central bank's instrument-rate plan. (3) When policy is credible, there would be little difference between these central-bank forecasts and market expectations for inflation, the output gap and interest rates. This means that market values of exchange rates and asset prices can without inconsistency be used as inputs in the projections.

paradox, that with multiple policy alternatives there may not be a policy that commands a majority vote against all alternatives (see, for instance, Person and Tabellini [38]). The proposal means that the MPC members vote simultaneously on the instrument rate for all future periods, by each member first writing down his/her preferred instrument rate for each period. The aggregate instrument rate for each period $t+\tau$, the median rate for that period, can then be seen as the result of voting on the instrument rate in that period, independently of the outcome of the voting for other periods. 
Goodhart [26, p. 175] presents another argument against time-varying instrument-rate plans, namely that a time-variable path would imply some degree of undesirable commitment to future policy actions, and that such commitments would be burdensome and undesirable. I am not convinced by that argument either. Observers of inflation-targeting central banks are already used to seeing published graphs of time-varying inflation and output-gap forecasts, and they have already learned that new information may warrant revisions of previously announced forecasts. There is no difference between revising a forecast of optimal time-varying interest rates due to new information and revising other forecasts. Furthermore, the Reserve Bank of New Zealand already publishes time-varying interest-rate forecasts that are revised when new information arrives, and during my review [45], I did not notice that this created any problems or misunderstanding by observers of the bank.

In addition, to the extent that published instrument-rate paths would be understood as some degree of commitment, this may actually be a good thing. It is a well-known result that optimal policy with forward-looking variables require a degree of history-dependence and inertia (as discussed in classic papers by Backus and Driffill [3] and Currie and Levine [16], and more recently by Woodford [57] and Svensson and Woodford [52]).

Once the central bank has settled on the preferred projections of inflation and the output gap, and the corresponding instrument-rate plan, transparency requires that it publishes these, as well as the preceding analysis and deliberations, in a regular publication, like the Inflation Reports of Bank of England and the Riksbank and the Monetary Policy Statement of the Reserve Bank of New Zealand. This way external observers can scrutinize and evaluate the analysis and decisions, which provides the best incentive for high quality analysis and decisions in the first place. Furthermore, the impact on inflation expectations and the term structure of interest rates is maximized, and the implementation of monetary policy thereby becomes most effective. The only thing that remains until next monetary-policy decision is then to set the instrument rate in accordance with the announced plan.

\section{Financial stability and asset prices}

\subsection{Financial stability}

Maintaining financial stability, including a well-functioning payment system, is an important objective for many central banks. How can this objective be reconciled with flexible inflation 
targeting, when do conflicts arise, and how can they be handled?

Does financial stability belong in the loss function for the central bank, together with inflation and the output gap? I believe the best way of handling this additional objective is as a constraint on monetary policy rather than as separate target variable that appears in the loss function. $^{27}$ The reason is that (at least in industrialized countries) under normal circumstances financial stability is good and does not pose any constraint on monetary policy. Only rarely, when financial crises occur, does financial stability impose constraints on monetary policy and force the central bank to modify its decisions. Typically, monetary policy is modified in a direction towards more expansionary policy, in order to improve the situation for a fledging financial sector, perhaps winning some time for a financial sector clean-up and reform. A transparent central bank would then explicitly announce when financial-stability concerns restrict its policy and motivate the corresponding deviation from normal policy (for instance, a deliberate overshooting of the inflation target). The nature of the constraint would seem to be quite complex and difficult to specify in advance, for instance, having to do with probability assessments of various bankruptcies in the financial sector. The complexity of the constraint of course makes it attractive to regard it as a constraint that does not bind and can be disregarded in normal times. $^{28}$

How does the central bank know whether the constraint binds or not? It knows by continually monitoring the state of the financial sector. In some countries, for instance, Sweden, the U.K., and Norway, the central bank publishes a regular Financial Stability Report (typically semiannually). This report includes analysis of indicators of the state of the financial sector, in particular early-warning indicators of potential future problems. (Producing and publishing such a regular report is one of the proposals for the Reserve Bank of New Zealand in my review [45].) These reports serve to assure the general public and economic agents that everything is well in the financial sector when this is the case. They also served as early warnings for the agents concerns and for the financial-regulation authorities when problems show up at the horizon. Early action can then prevent any financial instability to materialize, keeping the

\footnotetext{
27 There is an equivalence between a constraint and a modified loss function (this is the idea behind using a Lagrangian to solve a constrained optimization problem). In the same way as there is, for an import quota, an equivalent alternative (variable) import tariff, there is, for a given restriction, an equivalent alternative additional term in the loss function with an endogenous and nonlinear shadow price of the constraint. The endogeneity and nonlinearity of the shadow price make the additional term in the loss function more complex than a quadratic term, though.

${ }^{28}$ A constraint that binds in some situations and not in others introduces a nonlinearity. Then the conditions for certainty-equivalence, by which the mean projections of the target variables are sufficient, are no longer fulfilled. Strictly, the central bank should then apply the "distribution forecast targeting" referred to in footnote 19. Continuing to use mean projections may still be an acceptable approximation, more so the smaller the probability of the constraint binding.
} 
probability of future financial stability very low.

\subsection{Asset prices and bubbles}

Much recent discussion has focused on to what extent the central bank should take account of asset prices and, in particular, potential asset-price bubbles? In the forecast targeting described above, asset prices will affect policy to the extent they are deemed to affect the projections of the central bank's target variables, inflation and the output gap.

Suppose asset-price increases or an asset-price bubble is deemed to eventually increase spending on consumption and investment so that aggregate demand exceeds potential output. The central bank would then project a higher future output gap and higher future inflation, and, everything else equal, the central bank would respond with a tighter instrument-rate plan. Suppose a large asset-price increase is deemed to be fragile and a possible bubble, with a significant risk for a future collapse. Suppose further that a future collapse is deemed to have undesirable consequences for inflation and the output gap. Then the bank faces a delicate situation. It is possible that an instrument-rate plan with a higher instrument-rate in the near future will be deemed to dampen asset-price increases in the near future and also reduce the risk or size of a collapse in the farther future, this way providing a more stable development of inflation and the output gap. These are examples of situations when the central bank may choose to respond to asset-price developments. However, the reason for those responses is that the central bank is concerned with the repercussions for inflation and the output gap, not with the asset prices as such. That is, asset prices are not target variables; they do not enter the loss function. It goes without saying that in most realistic situations, it will be very difficult to judge whether a particular asset-price movement is grounded in expectations about reasonable fundamentals or a bubble, and whether there are repercussions on inflation and the output gap that motivate adjustment of the instrument-rate plan. This is obviously an area where good judgment is crucial. It is not a place for any mechanical adjustment to asset prices or bubbles. (Svensson [50] discusses the unavoidable role of judgment in monetary policy in greater detail.) The central bank's reaction will not be stable but shift with its judgment, and counter to substantial parts of the literature, I do not believe that is productive to discuss these issues directly in terms of the central bank's reaction function, for instance, as modifications of a Taylor rule. ${ }^{29}$

\footnotetext{
${ }^{29}$ The role of asset prices and bubbles in inflation target has been the subject of relatively intensive debate in, for instance, Batini and Nelson [7], Bernanke and Gertler [11] and [12], Cecchetti, Genberg, Lipsky and Wadhwani [14] and Cecchetti, Genberg and Wadhwani [14]. Most of this debate has been in terms of whether or not an instrument rule should include responses to asset prices and bubbles. This is, in my mind, too mechanical an
} 
Asset-price movements and asset-price bubbles may directly threaten financial stability and cause the financial-stability constraints on monetary policy to bind. Thus, the central bank may want to respond to asset price developments that bring increased risk of future financial instability. Again, in many realistic situations, the difficulty in making such judgments will be very large, and there will in many cases be insufficient information for taking such preemptive action.

Preemptive action to avoid future financial instability and corresponding future constraints on monetary policy is an example of preemptive avoidance of future restrictions on policy. It is from a principle point of view similar to preemptive action in order to avoid a future binding zero bound on the instrument rate, to be discussed in section 5. Furthermore, because a restriction that binds in some situations and not in others is inherently nonlinear, policy that attempts to avoid future restrictions will also tend to be nonlinear. Indeed, with nonlinear restrictions for objectives or in the transmission mechanism, optimal policy is nonlinear rather than linear.

\section{The zero bound, a liquidity trap and deflation}

Low inflation and low nominal interest rates imply some risk for hitting the zero (lower) bound for nominal interest rates. Flexible inflation targeting aimed at low and stable inflation and a stable output gap needs to take the zero bound, a liquidity trap and the risks of a deflationary spiral into account. The risk of the economy falling into a liquidity trap needs to be kept small. Ways of escaping from a liquidity trap, if the economy would ever fall in, also need to be considered..$^{30}$

Suppose the economy is hit by bad shocks that cause both a recession (a negative output gap) and deflation. The central bank would like to stimulate the economy (there is in this case no conflict between getting out of the recession and getting inflation back to normal) and lower the interest rate. The central bank can only lower the nominal instrument rate to zero. With deflation and expectations of deflation, the real interest rate (the nominal interest rate plus expectations of deflation) may still be higher than the level required to stimulate the economy out of recession and deflation. If the nominal interest rate is zero, the economy is satiated with liquidity. Open-market operations by the central bank to expand the monetary base by

approach to the question of whether or not inflation-targeting central banks should respond to the information contained in asset prices and bubbles. As discussed in Svensson [50], with judgment playing an essential role, the central-bank reaction function becomes overwhelmingly complex, and it is more practical to discuss policy in terms of the much simpler optimal targeting rule, the Euler condition of optimal monetary policy.

${ }^{30}$ Two conference volumes, Fuhrer and Sniderman [23] and Bank of Japan [48], discuss these issues at length. 
buying Treasury bills have no effect on prices and quantities (other than quantity of money and outstanding quantity of Treasury bills). The private sector is effectively indifferent between holding zero-interest-rate Treasury bills and money (once money holdings exceed the satiation point, the transactions and precautionary demand for money at a zero interest rate) and simply holds less Treasury bills and more money. This is a liquidity trap: expanding liquidity (the monetary base) beyond the satiation point has no effect. Because the real interest rate is too high, the economy may sink further into a spiral of deflation and depression. This is the nightmare of central bankers. Fortunately, it is a nightmare whose realization can be made very unlikely.

There are two parts of the solution to the problems associated with the zero bound and a liquidity trap. The first part concerns how to avoid hitting the zero bound and falling into a liquidity trap; the second part concerns how to escape from a liquidity trap after falling in.

As discussed more extensively in my contribution [43] to the Jackson Hole symposium 1999, a credible positive symmetric inflation target larger or equal to 1 percent (per year) is an effective way to avoid falling into a liquidity trap. An inflation target of 2 percent, say, provides an ample margin to the liquidity trap. Suppose transparent inflation targeting succeeds in making this target credible, so that private inflation expectations are anchored at the target. If the normal real interest rate is about 2 percent, the average nominal interest will then be about 4 percent. If the inflation target remains credible, so that inflation expectations remain about 2 percent, reducing the nominal interest rate to zero gives a real interest rate of minus 2 percent, 4 percentage points below the normal real interest rate. This would, in most cases, provide ample stimulus to the economy.

Indeed, forecast targeting as discussed above automatically means watching for changes in future inflation and reacting in time, well before actual inflation has turned into deflation. The MPC selecting the feasible projection of inflation and the output gap that minimizes the loss function as discussed in section 3 will automatically avoid projections and policy that get stuck in a liquidity trap. This is most effective if the loss function is symmetric around the inflation target (and is perceived to be so by the private sector), and if the central bank acts as decisively to inflation projections falling below the target as to those falling above. ${ }^{31}$

\footnotetext{
31 As for the restriction corresponding to financial stability discussed above (footnote 28), the zero bound implies a nonlinearity that strictly violates the certainty-equivalence results that implies that mean forecasts are sufficient to guide policy. In most cases, it is still probably an acceptable approximation to continue to use mean forecasts when the probability of the zero bound binding is positive. However, if the central bank deems that the approximation is not sufficiently good, it may need to shift to distribution-forecast targeting.
} 
The above goes a long way to prevent sustained deflation and a liquidity trap from ever materializing. Still, given the potential harm a liquidity trap and a deflationary spiral may cause, and given the small, but still positive risk that a series of unfortunate shocks may push even an exemplary inflation-targeting regime close to a liquidity trap, as discussed in more detail in [43], an additional safeguard for prudent central banks and fiscal authorities is to prepare for the worst and make advance contingency plans for a series of expansionary emergency measures to be undertaken at prescribed indications of an imminent liquidity trap.

\subsection{The foolproof way}

If the economy has fallen into a liquidity trap, with a zero nominal interest rate, deflation, and recession or even depression, there is as mentioned above no conflict between stabilizing the real economy and achieving the (positive) inflation target. From the point of view of both objectives, strongly expansionary policy is called for. As several authors have pointed out, an open economy has access to a very effective stimulative measure, namely a currency depreciation. From that insight, I have constructed a specific proposal, the foolproof way to escape from a liquidity trap, published as an academic article with all technical details, [48], in a conference volume from a conference organized by Bank of Japan and as a newspaper article, [44], in Financial Times. Although this proposal is directed to the Bank of Japan and the Ministry of Finance of Japan (the latter because the MOF is formally in charge of exchange rate policy in Japan), the foolproof way applies to any sufficiently open economy that has fallen into a liquidity trap. ${ }^{32} 33$

Getting Japan out of recession/depression and deflation arguably is arguably the world's most urgent monetary-policy task. Japan has already lost a decade to economic stagnation and deflation. Its monetary policy has been said to represent the world's worst monetary-policy mistake since the Great Depression. Without drastic policy measures, Japan may very well lose another decade. The zero-interest-rate policy implemented from February 1999 to August 2000, and again from March 2001, via the "quantitative easing" (expanding the monetary base), is not sufficiently expansionary to induce a recovery. With expectations of deflation, the real interest

\footnotetext{
${ }^{32}$ An ambitious Federal Reserve Board paper on preventing deflation and the lessons from Japan's experience strangely leaves out any discussion of a currency depreciation, Ahearne et al. [1, fn. 7]: "In this paper, we focus on the constraints to conventional monetary policy posed by the zero-lower-bound on nominal interest rates. We do not dispute the possibility of using other nonconventional means of monetary stimulus once the zero bound is reached-see Krugman (1998), Goodfriend (1997, 2000), Bernanke (2000), Clouse, Henderson, Orphanides, Small and Tinsley (2000), and Svensson (2001), among others, as well as Ueda (2001) for the BOJ's views toward such options. Nevertheless, we would agree with many analysts that once the zero bound is reached, reactivating the economy becomes more difficult and more uncertain."

33 See www.princeton.edu/ svensson/japan/japan.htm for more details on Japan and the foolproof way.
} 
rate remains positive. But the zero interest rate need not be the limit for monetary expansion. Indeed, there is a foolproof way to jump-start the Japanese economy. The BOJ (in charge of monetary policy) and the MOF (in charge of exchange rate policy) could cooperate to replace stagnation and deflation by growth and low inflation.

The foolproof way is to announce (1) an upward-sloping price-level target path to be achieved, (2) a depreciation and a temporary peg of the yen, and (3) the future abandonment of the peg in favor of inflation targeting when the price-level target path has been reached; then, the policy authorities just have to behave accordingly.

The price-level target path provides the best nominal anchor and also an exit strategy for the temporary peg. It can start above the current price level, by any "price gap" to be undone. Several years of zero or negative deflation may have resulted in a price level below previous expectations, increased the real value of debt and contributed to deteriorating balance sheets for firms and banks. The price gap may be 10-20 percent or more. The upward slope corresponds to a small positive inflation target appropriate to for Japan, 1 or 2 percent, say.

How to achieve the price-level target? This is the role of the depreciation and the temporary peg. First, a depreciation and temporary peg of the yen is technically feasible. If the peg would fail, the yen would appreciate back to where it was, making it a good investment. Thus, initially, before the peg's credibility has been established, there will be excess demand for yen. This is easily fulfilled, though, since the BOJ can print unlimited amounts of yen and sell those for foreign exchange. Indeed, there is a big difference between defending a fixed exchange rate for a strong currency under appreciation pressure (when foreign-exchange reserves rise) and for a weak currency under depreciation pressure (when foreign exchange reserves fall). Thus, the peg can be maintained, and after a day or a few, the peg's credibility will have been established.

Second, in order to be effective, the initial depreciation of the yen should be so large that it results in a real depreciation relative to any conceivable long-run equilibrium real exchange rate. This may require a peg at 140 or 150 yen to the dollar, or even more. Then the future must eventually bring a real appreciation. Thus, the market and the general public must expect a future real appreciation. But with an exchange rate peg, the real appreciation can only occur with a rise in the domestic price level. Hence, by pure logic, once the credibility of the exchange rate peg has been established, the market and the general public must expect future inflation in Japan. Thus, gloomy deflation expectations will be replaced by optimistic inflation expectations.

Third, the expected future real appreciation of the yen will induce a desirable fall in the long 
real interest rate in Japan. Indeed, equilibrium on the international capital market requires that the expected real return on investment in Japan and the rest of the world (including expected real exchange rate movements) move approximately in parallel. This fall in the long real rate in Japan can also be seen as the result of the increased inflation expectations noted above.

All this will jump-start the Japanese economy and increase output and the price level. First, the real depreciation will stimulate Japanese export and import-competing sectors. Second, the lower long real interest rate will stimulate Japanese consumption and investment. Aggregate demand and output will rise. Third, the real depreciation, the increased aggregate demand, and the increased inflation expectations will all contribute to inflation and an increasing price level.

The price level will approach the price-level target path from below. When the price-level target has been reached, the peg is abandoned, the yen floated, and the BOJ can adopt explicit inflation targeting.

The foolproof way can be followed unilaterally by Japan, without cooperation from countries in the region or from the U.S. The objections to a real depreciation of the yen that have been voiced by other countries in the region and some U.S. officials are mistaken. Expansion in Japan requires a lower real interest rate, and a real depreciation is the unavoidable mirror image of a lower real interest rate. A real depreciation means that Japanese exporters get a short-term competitive edge, but growth in Japan and increased aggregate demand will increase Japan's import from the rest of the world. A real depreciation has both a substitution and an income effect on the trade balance. These effects are of opposite signs. Thus, the real depreciation will tend to increase Japan's trade surplus. But the income effect, due to increased output, employment and income in Japan, will tend to reduce the trade surplus, because of Japan's increased import. Therefore, the net effect on the trade balance is probably quite small. The foolproof way is therefore not a beggar-thy-neighbor policy, except possibly in the very short run. In the medium and long run, the region, the US, and the world will gain substantially from an expansion in Japan. In particular, if the rest of the world is sluggish, Japan is needed even more as an engine of growth and trade.

Other proposals for Japan have focused on introducing inflation targeting (for instance, Bernanke [10], Krugman [30] and Posen [39]) and/or depreciating the yen (for instance, Bernanke [10], McCallum [31] and Meltzer [34]). The foolproof way is consistent with these proposals, but it provides better benchmarks, in the form of a peg for the yen, a price-level target path, and an exit strategy for the peg. The peg also provides an arena where the BOJ and the MOF can 
quickly demonstrate their resolve to end stagnation and deflation and thereby gain credibility.

Finally, the foolproof way is not a substitute for the structural reform and a clean-up of the financial sector in Japan that many observers recommend. Importantly, it is a complement rather than a substitute to these other policy actions.

Some commentators (The Economist [19] and Financial Times [18], as well as a number of newsletters from various investment banks) seem to assume that the only effects of a depreciation of the yen are a rise in the Japanese CPI due to increased import prices and a stimulation of exports. They have consequently concluded that the effect of an exchange-rate depreciation is more modest. As shown above, and fortunately for Japan, the effects of a depreciation and a peg of the yen depend on the whole policy package of the foolproof way and will therefore be much more widespread. Thus, the main effect of a depreciation of the yen and a peg is not the direct effect on CPI inflation trough domestic prices of imports (the direct exchangerate channel to CPI inflation mentioned in section 2). This direct exchange-rate effect is an additional effect to the ones mentioned above for the foolproof way. Thus, the foolproof way discussed increased inflation of domestically produced goods and services, that is, the Japanese GDP deflator, increased expectations of inflation in the GDP deflator, and increased demand for domestically produce goods and services from a lower real Japanese GDP-deflator interest rate, the nominal interest rate less inflation of the GDP deflator. Indeed, the "price level" referred to in the foolproof way is really the GPD-deflator, not the CPI. (This is made clear in the technical article [48] but not in the popular article [44]. The foolproof way can also be expressed in terms of the CPI price level, but the analysis is then slightly more complex.)

The foolproof way takes the rest of the world as given and, in particular, assumes that the rest of the world is not in a liquidity trap and a deflationary spiral but has positive inflation and a positive nominal interest rate (which has fortunately always been the case since the Great Depression). If the rest of the world would also be in a deflationary spiral (a highly unlikely outcome if the rest of the world has sufficiently positive inflation targets), it and Japan can obviously not apply the foolproof way at the same time.

Some commentators have been concerned about the fall in Japanese bond prices and corresponding negative balance-sheet effects that the foolproof way would cause. The foolproof way implies, once the temporary peg has become credible, that the Japanese short nominal interest rate has to rise above zero (to the level of the U.S. rate, if the peg is against the dollar). This implies that there will be a capital loss for holders of Japanese government bonds. However, 
these losses are gains of the same size for the Japanese government. If the losses are considered a problem, the government could compensate the losers by a subsidy, for instance, in the form of an increased coupon on the outstanding government bonds. Of course, any recovery and return to growth and expansion in Japan must imply an eventual increase in the short nominal interest rate above zero and therefore a capital loss on bonds. Avoiding that capital loss will mean avoiding a recovery. Furthermore, the total balance-sheet effects of the foolproof way, with lower real interest rates, increased demand, output, employment and profits, would seem to be overwhelmingly positive, with rises of stock prices and property values that would swamp any capital losses on government bonds.

Interestingly, since the current U.S. short nominal interest rate is low, the rise in the Japanese nominal rate from the foolproof way would be small. From this point of view, this may be a good time to initiate the foolproof way. Nevertheless, Japan would have been in better situation today, the earlier it would have initiated the foolproof way.

The foolproof way could jump-start Japan out of recession/depression and deflation. Not applying the foolproof way could mean another lost decade for Japan. The foolproof way can help any sufficiently open economy to escape from a liquidity trap. It belongs among the contingency plans that prudent central banks would want to prepare for the worst-case scenario of falling into a liquidity trap and risking a spiral of deflation and depression.

\section{Summary and conclusions}

The conclusions of this paper can be summarized in the following bullet points:

- In the long term, monetary policy can only control nominal variables such as inflation and the nominal exchange rate. It cannot increase the average level or the growth rate of real variables such as GDP and employment, or affect the average level of the real exchange rate. At best it can reduce the variability of real variables somewhat. In the short and medium term, monetary policy has effects on both nominal and real variables. However, the complex transmission mechanism of monetary policy, varying lags and strength of the effects through different channels, unpredictable shocks and inherent uncertainty combine to prevent any fine-tuning. There is general international support for a regime of flexible inflation targeting, where inflation is stabilized around a low inflation target in the medium term (rather than at the shortest possible horizon) and a gradual and measured policy re- 
sponse avoids creating unnecessary variability in the real economy. Monetary policy can achieve average inflation equal to a given inflation target and, at best, a good compromise between inflation variability and output-gap variability. Monetary policy cannot completely stabilize either inflation or the output gap. Increased credibility in the form of inflation expectations anchored on the inflation target will reduce the variability of inflation and the output gap.

- Central banks can improve transparency and accountability by specifying and announcing an explicit loss function for monetary policy. This actually boils down to just specifying one more number than the inflation target, namely a parameter with a simple interpretation, the dislike of output-gap variability relative to inflation variability. The Monetary Policy Committee can simply vote on the relative weight, as they vote on a number of other things. Specifying and announcing an explicit loss function will better focus the work inside the bank on achieving the optimal compromise between inflation stability around the inflation target and output stability around potential output, allow more precise external monitoring and evaluation of monetary policy, and allow more precise scrutiny and debate about the monetary-policy objectives.

- Central banks can best achieve both the long-run inflation target and the best compromise between inflation and output-gap stability by engaging in "forecast targeting," where at each major monetary-policy decision, the bank selects the feasible combination of inflation and output-gap projections that minimize the loss function and the corresponding instrument-rate plan and sets the instrument-rate accordingly. These projections are then the central bank's best unconditional forecasts of inflation, the output gap and the instrument rate. Announcing and motivating these forecasts maximize the impact on private-sector expectations and the economy and make the implementation of policy most effective. This allows the most effective external monitoring and evaluation of the policy, and thereby creates the strongest incentives for the bank to conduct good policy. It also allows precise debate about the monetary-policy objectives.

- Because of the variety and complexity of the information the central bank responds to and the unavoidable big role of judgment in its response, forecast targeting cannot be expressed in terms of a simple instrument rule, like a Taylor rule.

- Financial stability, including a well-functioning payment system, is an important additional 
objective for many central banks. This objective can conveniently be considered as a restriction on monetary policy that does not bind in normal times, but does bind in times of financial crises. Transparency then requires central banks to explain when this restrictions does bind and how it induces deviations from normal policy. By producing and publishing Financial Stability Reports with indicators of financial stability, the central bank can monitor the degree of financial stability and issue warnings to concerned agents and authorities in due time and this way avoid deteriorating financial stability.

- Forecast targeting implies that asset-price developments and potential asset-price bubbles are taken into account and responded to the extent that they affect the projections of the target variables, inflation and the output gap. Situations can arise when asset-price developments are deemed unsustainable and hence bubbles, and when a future collapse is deemed likely. If the probability of such a future collapse is deemed to impact on inflation or output gap projections, the central bank may want adjust policy to moderate the assetprice developments and reduce the probability of future collapses, thereby achieving more preferable inflation and output-gap projections. In most cases, it will be difficult to make such precise judgments, though, especially to identify bubbles with reasonable certainty.

- The zero bound, liquidity traps and risks of deflation are serious concerns for a monetary policy aimed at low inflation. A symmetric positive inflation target is likely to provide sufficient margin to those risks. Forecast targeting with such an inflation target will avoid the zero bound, liquidity traps and deflation. Prudent central banks and ministries of finance may want to prepare in advance contingency plans for situations when a series of bad shocks substantially increases the risk of falling into a liquidity trap, as well as contingency plans for how to escape from a liquidity trap if the economy has fallen in. An open economy, such as Japan, can use the foolproof way to escape, with a price level target, a currency depreciation and a temporary exchange rate peg, and an exit strategy with a shift to inflation target when the price-level target has been reached.

\section{References}

[1] Ahearne, Alan, Joseph Gagnon, Jane Haltmaier, Steve Kamin, Christopher Erceg, Jon Faust, Luca Guerrieri, Carter Hemphill, Linda Kole, Jennifer Roush, John Rogers, Nathan 
Sheets and Jonathan Wright (2002), "Preventing Deflation: Lessons from Japan's Experience in the 1990s," International Finance Discussion Paper No. 729, Federal Reserve Board.

[2] al-Nowaihi, Ali, and Livio Stracca (2001), "Non-Standard Central Bank Loss Functions, Skewed Risks, and the Certainty-Equivalence Principle," working paper.

[3] Backus, David, and John Driffill (1986), "The Consistency of Optimal Policy in Stochastic Rational Expectations Models," CEPR Discussion Paper No. 124.

[4] Bank of England (2000), Inflation Report, November 2000, Bank of England.

[5] Bank of Japan (2000), The Role of Monetary Policy under Low Inflation: Deflationary Shocks and Policy Responses, Monetary and Economic Studies 19(S-1), Bank of Japan, .

[6] Batini, Nicoletta, and Andrew G. Haldane (1999), "Forward-Looking Rules for Monetary Policy," in John B. Taylor, ed., Monetary Policy Rules, Chicago University Press, 157-192.

[7] Batini, Nicoletta, and Edward Nelson (2000), "When the Bubble Bursts: Monetary Policy Rules and Foreign Exchange Market Behavior," working paper.

[8] Batini, Nicoletta, and Edward Nelson (2001), "Optimal Horizons for Inflation Targeting," Journal of Economic Dynamics and Control 25, 891-910.

[9] Berg, Claes, and Lars Jonung (1999), "Pioneering Price Level Targeting: The Swedish Experience 1931-1937," Journal of Monetary Economics 43, 525-551.

[10] Bernanke, Ben S. (2000), "Japanese Monetary Policy: A Case of Self-Induced Paralysis?" in Adam Posen and Ryoichi Mikitani, eds., Japan's Financial Crisis and Its Parallels to US Experience, Special Report 13, Institute for International Economics, Washington, DC, 149-166.

[11] Bernanke, Ben, and Mark Gertler (1999), "Monetary Policy and Asset Price Volatility," in Federal Reserve Bank of Kansas City [22], 77-128.

[12] Bernanke, Ben, and Mark Gertler (2001), "Should Central Banks Respond to Movements in Asset Prices?" American Economic Review: Papers and Proceedings 91, 253-257.

[13] Bernanke, Ben S., and Frederic S. Mishkin (1997), "Inflation Targeting: A Strategy for U.S. Monetary Policy?" Journal of Economic Perspectives 11(2), 97-116. 
[14] Cecchetti, Stephen G., Hans Genberg, John Lipsky and Sushil Wadhwani (2000), Asset Prices and Central Bank Policy, Geneva Report on the World Economomy 2, CEPR and ICMB, Geneva.

[15] Cecchetti, Stephen G., Hans Genberg and Sushil Wadhwani (2002), "Asset Prices in a Flexible Inflation Targeting Framework," working paper.

[16] Currie, David, and Paul Levine (1993), Rules, Reputation and Macroeconomic Policy Coordination, Cambridge University Press, Cambridge.

[17] Debelle, Guy (1999), "Inflation Targeting and Output Stabilization," Research Discussion Paper 1999-08, Reserve Bank of Australia.

[18] Finacial Times (2002), "Japan plays its final card in battle to revive growth," FT.com, Jan 8, 2002.

[19] The Economist (2002), "On the slide," The Economist, Jan 5, 2002.

[20] Ehrmann, Michael, and Frank Smets (2002), "Undertain Potential Output: Implications for Monetary Policy," Journal of Economic Dynamcis and Control, forthcoming.

[21] Federal Reserve Bank of Kansas City (1996), Achieving Price Stability, A Symposium Sponsored by the Federal Reserve Bank of Kansas City, Kansas City.

[22] Federal Reserve Bank of Kansas City (1999), New Challenges for Monetary Policy, A Symposium Sponsored by the Federal Reserve Bank of Kansas City, Kansas City.

[23] Fuhrer, Jeffrey C., and Mark S. Sniderman, eds., (2002), Monetary Policy in a Low-Inflation Environment, Journal of Money Credit and Banking 84, 845-1109.

[24] Gaspar, Vitor, and Frank Smets (2002), "Monetary Policy, Price Stability and Output Gap Stabilisation," working paper, European Central Bank.

[25] Goodfriend, Marvin (1993), "Interest Rate Policy and the Inflation Scare Problem: 197992," Federal Reserve Bank of Richmond Economic Quarterly 79: 1-24.

[26] Goodhart, Charles A.E. (2001), "Monetary Transmission Lags and the Formulation of the Policy Decision on Interest Rates," Federal Reserve Bank of St. Louis Review July/August 2001, 165-181. 
[27] Heikensten, Lars (1999), "The Riksbank's Inflation Target-Clarification and Evaluation," Sveriges Riksbank Quarterly Review 1/1999, 5-17.

[28] King, Mervyn A. (1994), "Monetary Policy in the UK," Fiscal Studies 15, No. 3, 109-128.

[29] Kohn, Donald L. (2000), "Report to the Non-Executive Directors of the Court of the Bank of England on Monetary Policy Processes and the Work of Monetary Analysis," Bank of England.

[30] Krugman, Paul (1998), "It's Baaack! Japan's Slump and the Return of the Liquidity Trap," Brookings Papers on Economic Activity 2:1998, 137-187.

[31] McCallum, Bennett T. (2000), "Theoretical Analysis Regarding a Zero Lower Bound on Nominal Interest Rates," Journal of Money Credit and Banking 84, 870-904.

[32] McCallum, Bennett T., and Edward Nelson (1999), "Performance of Operational Policy Rules in an Estimated Semi-Classical Structural Model," in John B. Taylor., ed., Monetary Policy Rules, Chicago University Press, 15-45.

[33] Meltzer, Allan H. (1986), "Limits of Short-Run Stabilization Policy: Presidential Address to the Western Economic Association," Economic Inquiry 25, 1-14.

[34] Meltzer, Allan H. (1999), "Commentary: What More Can the Bank of Japan Do?" Monetary and Economic Studies 17(3), Bank of Japan, 189-191.

[35] Meyer, Laurence H. (2001), "Inflation Targets and Inflation Targeting," Speech at University of California at San Diego Economics Roundtable, San Diego, July 17, 2001.

[36] Nobay, Robert P., and David A. Peel (1998), "Optimal Monetary Policy in a Model of Asymmetric Central Bank Preference," FMG Discussion Paper No. 306.

[37] Orphanides, Athanasios, and John C. Williams (2002), "Imperfect Knowledge, Inflation Expectations and Monetary Policy," working paper, Federal Reserve Board.

[38] Persson, Torsten, and Guido Tabellini (2000), Political Economics: Explaining Economic Policy, MIT Press, Cambridge, MA.

[39] Posen, Adam S. (1998), Restoring Japan's Economic Growth, Institute for International Economics, Washington, DC. 
[40] Rogoff, Kenneth (1985), "The Optimal Degree of Commitment to a Monetary Target." Quarterly Journal of Economics 100, 1169-1190.

[41] Ruge-Murcia, Francisco J. (1999), "Inflation Targeting under Asymmetric Preferences," working paper.

[42] Svensson, Lars E.O. (1997), “Optimal Inflation Targets, 'Conservative' Central banks, and Linear Inflation Contracts," American Economic Review 87, 98-114.

[43] Svensson, Lars E.O. (1999), "How Should Monetary Policy Be Conducted in an Era of Price Stability?" in Federal Reserve Bank of Kansas City [22].

[44] Svensson, Lars E.O. (2001a), "How Japan Can Recover," Financial Times, Sep 25, 2001.

[45] Svensson, Lars E.O. (2001b), "Independent Review of the Operation of Monetary Policy in New Zealand: Report to the Minister of Finance," February 2001, www.princeton.edu/ ${ }^{\sim}$ svensson.

[46] Svensson, Lars E.O. (2001c), "Price Stability as a Target for Monetary Policy: Defining and Maintaining Price Stability," in Deutsche Bundesbank, ed., The Monetary Transmission Process: Recent Developments and Lessons for Europe, Palgrave, New York, 60-102. (Also available as CEPR Discussion Paper No. 2196.)

[47] Svensson, Lars E. (2001d), "Requiem for Forecast-Based Instrument Rules," working paper.

[48] Svensson, Lars E.O. (2001e), "The Zero Bound in an Open-Economy: A Foolproof Way of Escaping from a Liquidity Trap", Monetary and Economic Studies 19(S-1), Bank of Japan, $277-312$.

[49] Svensson, Lars E.O. (2002a), "The Inflation Forecast and the Loss Function," in Paul Mizen, ed., Central Banking, Monetary Theory and Practice: Essays in Honour of Charles Goodhart, Edward Elgar, forthcoming.

[50] Svensson, Lars E.O. (2002b), "What is Wrong with Taylor Rules? Using Judgment in Monetary Policy through Targeting Rules," Journal of Economic Literature, forthcoming.

[51] Svensson, Lars E.O., Kjetil Houg, Haakon Solheim and Erling Steigum (2002), "An Independent Review of Monetary Policy and Institutions in Norway," Centre for Monetary Economics, Norwegian School of Management, in preparation. 
[52] Svensson, Lars E.O., and Michael Woodford (2002), "Implementing Optimal Policy through Inflation-Forecast Targeting," working paper.

[53] Taylor, John B. (1979), "Estimation and Control of a Macroeconomic Model with Rational Expectations," Econometrica 47, 1267-1286.

[54] Vickers, John (1998), "Inflation Targeting in Practice: the UK Experience," Bank of England Quarterly Bulletin 38, 368-375.

[55] Wallis, Kenneth F. (1999), "Asymmetric Density Forecasts of Inflation and the Bank of England's Fan Chart," National Institute Economic Review No.167 (January), 106-112.

[56] Woodford, Michael (1999a), "Commentary: How Should Monetary Policy Be Conducted in an Era of Price Stability?" in Federal Reserve Bank of Kansas City [22], 277-316.

[57] Woodford, Michael (1999b), "Optimal Monetary Policy Inertia," working paper. 